good prognosis so far as the establishment of menstruation is concerned in the case of a girl of 16 or 17 ; at 18 or 19 the prognosis must be more guarded and the effect of treatment must be watched; while after the age of 20 no opinion should be expressed without making an examination.

Then we must be guided to some extent by the general liealth of the patient. If she be suffering from anæmia, tuberculosis, or some other constitutional condition that may cause amenorrhcea we may hope (with the proviso of age just considered) that menstruation will begin when the general condition has improved.

But supposing the general condition to be good, and the patient 20 years of age, or older, the development of breasts and pubic hair should be noted (for any marked deficiency in these secondary sexual characters is unfavourable), and a pelvic examination should be made-under an anæsthetic if unmarried. If no abnormality can be found, or the uterus be only slightly under the normal size, the prognosis is not unfavourable; on the other hand if the uterus is very small, or if the ovaries are very small and infantile in shape, the probability is against the establishment of menstruation.
With regard to the child-bearing, if the pelvic organs are found to be normal we can say that if the patient be 18 and menstruation has not yet appeared the prognosis is still fairly good; if she is 19 , she is more likely to be relatively, although not absolutely, unfertile; while if 20 or over the likelihood of child bearing rapidly diminishes in proportion to age. If she is 25 , and still has not ; menstruated, she will almost certainly be sterile, as also will be the case if the uterus is undeveloped, the uterine canal measuring 2 inches or less.

$$
{ }^{1} \text { Clin. Jour., Jan. } 30 .
$$

\section{THE TREATMENT OF URIC-ACID GRAVEL.}

DR. GEE, writing in the St. Bartholomew's Hospital Journal, says that he has found a very efficacious remedy for uric-acid gravel in the use of fresh whey as a drink. A large teacupful taken after each meal has not yet failed, he says, so far as his present experience goes, in prevent-. ing the appearance of uric-acid gravel, even in persons who. have been subject to it for a considerable time. This seems. a safe and simple remedy enough, and one well worthy of a trial.

\title{
Progress in State Medicine.
}

HOUSING OF THE WORKING CLASSES.

"THE ${ }^{1}$ greatest hindrance to the progress of preventive medicine which we have to overcome is the overcrowded and insanitary condition of the dwellings of the working classes." This statement was quoted by Tew ${ }^{2}$ whilst speaking on the provision of cottages in rural districts for the working classes and its bearing upon the public health. Combat is not directly with the microbe, but with the surroundings in which it thrives. To determine what is a rural district he favoured some such division as the following: (1) Metropolis proper ; (2) suburban districts where the question of accommodation was somewhat less acute than in the centre of London; (3) extra-suburban districts, i.e. just beyond the immediate suburbs, but which were fast being absorbed into the suburbs of the spreading metropolis; (4) agricultural districts where the inhabitants worked on the land; (5) cities and large provincial towns where special conditions of situation, industries, \&c., made the question of provision of further dwelling accommodation purely local; (6) suburbs of cities and large provincial towns which must be dealt with on their own merits. Of these 3,4 , and 6 would come under the heading of rural districts. The working people resolve themselves into three classes : (1) In good work, wages 25 s. to 30 s. a week, but whose greatest difficulty is in procuring decent dwellings, rents being from $6 \mathrm{~s}$. $6 \mathrm{~d}$. to $8 \mathrm{~s}$. 6d. a week. This led to the inevitable lodgers, and consequent overcrowding. (2) Ordinary agricultural labourers, wages $12 \mathrm{~s}$. to $22 \mathrm{~s}$. On large estates this class is often well housed, rent $1 \mathrm{~s}$. to $2 \mathrm{~s}$. 6d. per week, with ga and supply of milk: In others the cottages might be cheap, under 2 s., but were small, damp, and ill-drained. The remainder lived in their own cottages, which are generally mortgaged, and rarely in a satisfactory condition. (3) Those having no regular occupation, and having an alternating existence between a slum cottage, the workhouse, the gaol, and the road. The children of these were active agents in the spread of infectious and parasitic diseases in our elementary schools. The foremost evil was the lowering of the individual stamina of those living under bad conditions; next the two diseases--- measles and whooping cough-which in 1899 accounted for 19,000 deaths, mostly among the children of the working classes. Obstacles to the provision of adequate cottages were many and great, and although increased powers had been available for ten years, only two rural district councils in England had reached the state of actual buildings. The annual re-election of sanitary inspectors and medical officers of health was often jeopardised by local interests. Fresh houses should be provided before closing insanitary ones. Where land was not big-priced rural councils, could build cottages just to pay their way, but even should there be a loss on them such loss must be looked on as an insurance premium on the health of the place. Groves $^{3}$ is of opinion that the landlords receiving such. small returns as rent could not afford repairs, and so forced. the labourers from the condemned houses into the nearest. towns. Security of tenure for all sanitary officials was, the only safeguard, and that could be obtained only from the Local Government Board. Welton ${ }^{4}$ draws attention. to the fact that at the time of the first census 36 per cent. of the people lived in towns of 1,000 inhabitants and upwards, but in 189164 per cent. of the people lived in. towns exceeding 4,000 in population. The ordinary density of population in rural districts was in 1801 about; 100 persons per square mile; in 1891 it averaged 130 persons. Since 1851 there has been an actual decline in rural population.

Pattin ${ }^{5}$ remarks that by workmen's dwellings he means homes suitable for poor men rather than artisans, or skilled artisans. The need for action is emphasised by the fact that, in Manchester alone, out of 11,000 wouldbe recruits, 90 per cent. were excluded from the regular army on the ground of physical unfitness. Inefficientlyequipped and managed common lodging-houses damaged the health of the community. The credit of the municipality is greater than that of the individual who is trading for a profit, and therefore it is easier for it to carry. on common lodging-houses and provide poor men's cottages more cheaply than the private individual. The advantages from this would be an improved generation through healthier surroundings, and more air space; also the 